\title{
Land Surface Temperature from Landsat 5 TM images: comparison of different methods using airborne thermal data
}

\author{
M. B. Giannini, O. R. Belfiore, C. Parente* and R. Santamaria \\ Department of Sciences and Technologies, University of Naples “Parthenope”, Naples, Italy. \\ Received 18 June 2015; Accepted 18 October 2015
}

\begin{abstract}
In this study, several methods to compute land surface temperatures (LST) from Landsat TM5 data are compared. Two different approaches are considered. An image based approach that takes into account atmospherically corrected data by using a dark object subtraction model (DOS-1) and computes the emissivity as NDVI function. The emissivity of a surface is controlled by such factors as water content, chemical composition, structure and roughness; it can be determined as the contribution of the different components that belong to the pixels according to their proportions. NDVI method takes into account that vegetation and soils are the main surface cover for the terrestrial component. This emissivity is used to compute the LST by the inversion of Planck function. The other approach applies atmospheric correction to thermal infrared band and considers a constant emissivity of 0.95 . Furthermore, the land surface temperature is computed by hybrid methods that result from the merger of the two initially considered approaches. These results are compared with the surface temperature measured by airborne Multispectral Infrared and Visible Imaging Spectrometer (MIVIS). The LST measured by MIVIS sensor can be considered closer to the real surface temperature because the data are acquired at an altitude of $1500 \mathrm{~m}$ and are not affected by significant atmospheric effects such as for satellite data, acquired at $705 \mathrm{~km}$ from the Earth's surface. The best results are obtained by considering variable emissivity.
\end{abstract}

Keywords: Remote Sensing, Land Surface Temperature, emissivity, Landsat 5 TM.

\section{Introduction}

The Thematic Mapper (TM) sensor on board of the Landsat4 and Landsat-5 satellites supplies images of the Earth's surface in seven spectral bands, of which six cover the visible and shortwave infrared parts of the electromagnetic spectrum $(0.5-2.5 \mu \mathrm{m})$ and one the thermal infrared "emissive" part of it (10.4-12.5 $\mu \mathrm{m})$.

The spatial resolution of these images is $30 \mathrm{~m} \times 30 \mathrm{~m}$ for the reflective bands and $120 \mathrm{~m} \times 120 \mathrm{~m}$ for the emissive one. Landsat 4 was launched on 16 July 1982 and termineted its mission after 11 years, 4 months and 28 days (on December 14, 2003). Even if its expected lifetime was shorter, Landsat 5, that was launched on March 1, 1984, remained operational until 5 June, 2013. On board of the Landsat-7 satellite, launched on April 15, 1999 and still active, there is the Enhanced Thematic Mapper plus (ETM+) sensor that in addition to the same bands of the TM presents the panchromatic band $(0.52-0.90 \mu \mathrm{m})$ with $15 \mathrm{~m}$ spatial resolution. While the pixel dimensions of the images provided by ETM+ in the reflective bands are the same of the corresponded ones of TM, for emissive band they have been improved from 120 to $60 \mathrm{~m}$ and data are available in two gain states.

To obtain Land Surface Temperature (LST) from thermal images, many methods are present in literature: the first approaches to be developed, such as the so-called split-

* E-mail address: claudio.parente@uniparthenope.it ISSN: 1791-2377 @ 2015 Kavala Institute of Technology. All rights reserved. window methods [1] [2], required the availability of two images in adjacent infrared bands while TM provided only one. For this reason at the beginnings band TM6 was not used for environmental studies as the other bands of the same sensor [3].

The split-window methods are based on the differential absorption in adjacent infrared bands: e.g. in 1984 data in split window channels at 10.8 and $11.9 \mu \mathrm{m}$ from the Advanced Very High Resolution Radiometer (AVHRR) on the NOAA 7 satellite were used to estimate surface temperature and the atmospheric correction to radiation from the Earth's surface [4].

To obtain LST from one infrared channel, additional information is necessary such as surface emissivity and temperature/water vapor profile. The first may be obtained from a classification image, in which an emissivity value for each class is assumed, but this approach is limited because a good knowledge of the study area and emissivity is required [3]. Other approaches to define surface emissivity can be adopted, such as those based on NDVI (Normalized Difference Vegetation Index) use [5] [6] [7].

Temperature/water vapor profile can be obtained by either satellite soundings or conventional radio soundings [1]. The corrections for atmospheric absorption, atmospheric emission, and surface emissivity are not easy to be defined, so the development of accurate LST algorithms is difficult [8].

This paper is aimed to compare different methods to retrieve LST from one thermal image supplied by TM 5 sensor. To evaluate the different results, temperature derived by the airborne Multispectral Infrared and Visible Imaging 
Spectrometer (MIVIS) is considered. The paper is structured in the following way. In section 2 satellite and airborne data as well as the applied methods are presented. In section 3 the results are reported and discussed. Final considerations are in Section 4.

\section{Data and methods}

\subsection{Remotely sensed data and study area}

In this study, Landsat TM5 satellite and MIVIS images are used for retrieval of the land surface temperatures on rural areas, in Campania Region (Fig. 1). As reported in the previous sector, the satellite images are acquired in seven spectral bands with a spatial resolution of 30 meters for Bands 1 to 5 and 7. Spatial resolution for Band 6 (thermal infrared) is 120 meters, but is resampled to 30 -meter pixels [9]. All TM images have been acquired the $9^{\text {th }}$ of August (at 9:30:18 GMT), in 2011. The MIVIS is a hyperspectral sensor that acquires in 102 spectral bands, from the Visible to Thermal Infrared, with a spatial resolution of 3-m ground pixel at an altitude of $1500 \mathrm{~m} \mathrm{[10].}$

In this paper only thermal images by MIVIS are considered. The thermal data acquired by MIVIS range from 8.2 to $12.7 \mu \mathrm{m}$. These are radiometrically calibrated and at the sensor temperatures are calculated with a linear interpolation between the reference values of two black bodies allocated in the MIVIS sensor.

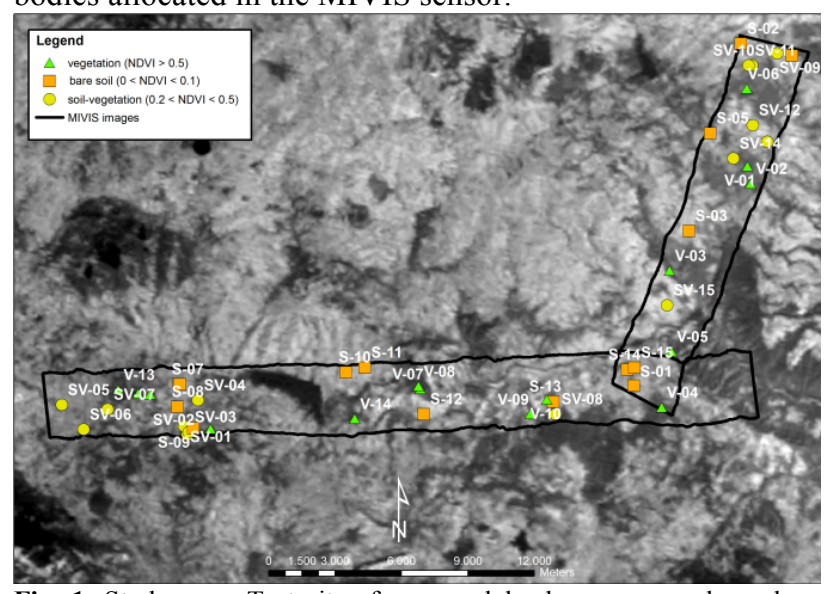

Fig. 1. Study area. Test sites for several land covers are showed on Band 6 of the Landsat TM5 satellite

\subsection{Image pre-processing}

In raw remote sensing data, each pixel has a digital number value that corresponds to a raw measure acquired by the sensor.

To obtain quantitative information from images, digital number must be converted to physical quantities, radiance and brigthness temperature for this study. It is then necessary to correct the previously calibrated images by atmospheric effects. The presence of the atmosphere can cause significant distortions in the radiometric signal. The standard Landsat TM5 products consist of quantized and calibrated scale digital number representing multispectral image data. The images can be converted to Top of Atmospere (TOA) radiances using the following expression:

$$
L_{\lambda}=\left(\frac{{ }_{M A X}{ }^{-L_{M I N}} \lambda}{Q_{c a l} l_{M A X}}\right) Q_{c a l}+L_{M I N} \lambda
$$

where $\mathrm{Q}_{\mathrm{cal}}$ is quantized calibrated pixel value in DNs, $\mathrm{L}_{\mathrm{MIN} \lambda}$ is spectral radiance corresponding to $\mathrm{Q}_{\text {calMIN }}(\mathrm{DN}=0)$, $\mathrm{L}_{\mathrm{MAX} \lambda}$ is spectral radiance corresponding to $\mathrm{Q}_{\text {calMAX }}(\mathrm{DN}=$ 255). The above expression can also be written as follows [9]:

$$
L_{\lambda}=G_{\text {rescale }} \cdot Q_{\text {cal }}+B_{\text {rescale }}
$$

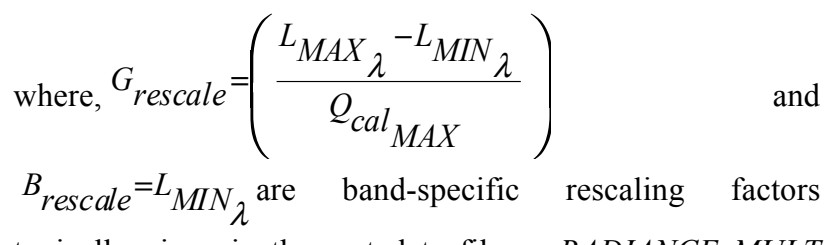
typically given in the metadata file as RADIANCE MULT $B A N D$ and RADIANCE ADD BAND.

$\mathrm{L}_{\lambda}$ does not consider the atmospheric effects, therefore it is necessary to convert images from radiance to reflectance measures.

Therefore, it needs to account for atmospheric correction effects using specific correction methods. At the aim, two different approaches are used, image based methods and a radiative transfer model. The image based approaches most used are known as DOS (Dark Object Subtraction) and in this study it is considered the DOS-1 model.

DOS-1 is applied to only multispectral images data. The DOS models main advantages are that it is strictly an image-based procedure and does not require in situ field measurements. DOS-1 assumes that only some pixels are in complete shadow into image and their at sensor radiances are due to atmospheric scattering.

This assumption is combined with the fact that few targets on the Earth's surface are absolute black (dark object), so an assumed one percent minimum reflectance is better than zero percent [11]. Besides correcting for the same parameters, that the apparent reflectance model does, the image based DOS radiometric correction model also corrects for atmospheric additive scattering component, attributed to the path radiance [11].

The equation to convert the at satellite radiances to surface reflectance, correcting for both solar (solar irradiance and solar zenith) and atmospheric effects, according with Moran [12] and Sobrino [3] is:

$$
\rho_{\text {sup }}(\lambda)=\frac{\pi \cdot\left[L_{\text {sat }}(\lambda)-L_{p}(\lambda)\right] d^{2}}{\tau_{v}(\lambda) \cdot\left[E_{0}(\lambda) \cdot \cos \left(\vartheta_{z}\right) \cdot \tau_{z}(\lambda)+E_{d o m n}(\lambda)\right]}
$$

where, $\mathrm{L}_{\mathrm{sat}}(\lambda)$ is the at satellite sensor radiance; $\tau_{\mathrm{v}}(\lambda)$ and $\tau_{\mathrm{z}}(\lambda)$ are the atmospheric trasmittances along path from the ground surface to the sensor and vice versa, respectively; $\vartheta_{z}$ is the zenithal solar angle; $\mathrm{E}_{0}(\lambda)$ is the solar spectral irradiance on a surface perpendicular to the sunrays outside the atmosphere and contains the square Earth-Sun distance term $\left(d^{2}\right)$ imbedded and is in astronomical units; $E_{\text {down }}(\lambda)$ is the downwelling spectral radiance at the surface due to scattered flux in the atmosphere; $L_{p}(\lambda)$ is the path radiance resulted from the interaction of electromagnetic radiance with the atmospheric components (molecules and aerosol).

In DOS-1 radiance-reflectance model, $\tau_{\mathrm{v}}(\lambda)$ and $\tau_{\mathrm{z}}(\lambda)$ are equal to 1.0 (ignores atmospheric trasmittance), the downwelling spectral irradiance is ignored $\left(\mathrm{E}_{\text {down }}(\lambda)=0\right)$ and surface reflectance can be computed by the following expression: 


$$
\rho_{\text {sup }}(\lambda)=\frac{\pi \cdot\left[L_{s a t}(\lambda)-L_{p}(\lambda)\right] d^{2}}{E_{0}(\lambda) \cdot \cos \left(\vartheta_{z}\right)}
$$

where, $\mathrm{L}_{\mathrm{p}}(\lambda)=\mathrm{L}_{\min }(\lambda)-\mathrm{L}_{1 \%}(\lambda), \mathrm{E}_{0}(\lambda)$ is the solar exoatmospheric irradiance $\left(\mathrm{E}_{\mathrm{SUN} \lambda}\right) . \mathrm{L}_{\min }(\lambda)$ is the radiance that corresponds to a digital count value for which the sum of all pixels with digital counts lower or equal to this value is equal to $0.01 \%$ of all the pixels from the considered image [3]. $\mathrm{L}_{1 \%}(\lambda)$ is the dark object radiance and can be computed with following expression:

$$
L_{1 \%}(\lambda)=\frac{0.01 \cdot \cos \left(\vartheta_{z}\right) \cdot E_{0}(\lambda)}{\pi \cdot d^{2}}
$$

\subsection{Retrieval of land surface temperature}

The next step is to convert the spectral radiance to TOA brightness temperature under the assumption of uniform emissivity by the following equation:

$$
T_{B}=\frac{K_{2}}{\ln \left(\frac{K_{1}}{L_{\text {sat }}}+1\right)}
$$

where, $T_{B}$ is at-satellite brightness temperature $(K), L_{\text {sat }}$ is the spectral radiance $\left(\mathrm{W} / \mathrm{m}^{2} *_{\mathrm{sr}} * \mu \mathrm{m}\right), \mathrm{K} 2$ is the calibration constant $(\mathrm{K}), \mathrm{K} 1$ is the calibration constant $\left(\mathrm{W} / \mathrm{m}^{2} * \mathrm{sr} * \mu \mathrm{m}\right)$.

The correct determination of the surface temperature is constrained to an accurate knowledge of surface emissivity. The emissivity of a surface is controlled by such factors as water content, chemical composition, structure and roughness [13]. It can be determined as the contribution of the different components that belong to the pixels according to their proportions. The relationship between LST and NDVI takes into account that vegetation and soils are the main surface cover for the terrestrial component. In this study, we consider two different NDVI methods. The first computes an emissivity image by following equation:

$$
\varepsilon=a+b \cdot \ln (N D V I)
$$

where, $\mathrm{a}=1.0094$ and $\mathrm{b}=0.047$ are obtained by $\mathrm{a}$ regression analysis based on a large dataset [14].

NDVI is calculated from the values of reflectance of the Visible and Near Infrared bands:

$$
N D V I=\frac{\rho_{N I R}-\rho_{R E D}}{\rho_{N I R}+\rho_{R E D}}
$$

where, $\rho_{N I R}$ and $\rho_{R E D}$ are the reflectances obtained by applying the DOS- 1 method at the band 4 and the band 3 of $\mathrm{TM}$, for atmospheric effect correction.

NDVI is function that varies in the range $[-1,+1]$. Negative values correspond to water, values close to zero, but positive values correspond to soils and further, from 0.2 to 0.6 indicate the presence of surfaces vegetated with maximum values around 0.8 for very dense vegetation [14].

The next NDVI method [3] calculates an image emissivity and considers three cases. If NDVI $<0.2$ then the pixel is considered as bare soil and a mean value of 0.97 is assumed for the emissivity. If NDVI $>0.5$, the pixels correspond to dense vegetation areas and they are given an emissivity value of 0.99 . Finally, if $0.2 \leq \mathrm{NDVI} \leq 0.5$, each pixel corresponds to a mixing of bare soil and vegetation, and the emissivity can be computed according to the following equation:

$$
\varepsilon=\varepsilon_{v} \cdot P_{v}+\varepsilon_{S} \cdot\left(1-P_{v}\right)+d \varepsilon
$$

where, $\varepsilon_{v}$ e $\varepsilon_{s}$ are vegetation and soil emissivity, $d \varepsilon$ includes the effect of the geometrical distribution of the natural surfaces and also the internal reflections (i.e. forest). This term is calculated by the following expression [3] [15]:

$d \varepsilon=\left(1-\varepsilon_{S}\right) \cdot\left(1-P_{v}\right) \cdot F \cdot \varepsilon_{v}$

In this equation, $\mathrm{F}$ is a shape factor [15] and assumes a mean value of 0.55 , assuming different geometrical distributions. $\mathrm{P}_{\mathrm{v}}$ is the vegetation proportion obtained according to Carlson and Ripley [16]:

$$
P_{v}=\left[\frac{N D V I-N D V I_{\min }}{N D V I_{\max }-N D V I_{\min }}\right]^{2}
$$

where, $\mathrm{NDVI}_{\max }=0.5$ and $\mathrm{NDVI}_{\min }=0.2$.

The final expression for the emissivity, after a few steps [3], is given by:

$$
\varepsilon=0.004 \cdot P_{v}+0.986
$$

The land surface temperatures corrected for spectral emissivity $(\varepsilon)$ is computed as follows [17]:

$$
L S T=\frac{T_{B}}{1+\left(\frac{\lambda \cdot T_{B}}{\rho}\right) \cdot \ln (\varepsilon)}
$$

where, $\lambda$ is the central band wavelength of emitted radiance $(11.45 \mu \mathrm{m}), \rho=h^{*} c / \sigma\left(1.438 * 10^{-2} \mathrm{~m} * \mathrm{~K}\right)$ with: $\sigma$ is the Boltzmann constant $\left(1.38^{*} 10^{-23} \mathrm{~J} / \mathrm{K}\right), h$ is the Planck's constant $\left(6.626^{*} 10^{-34} \mathrm{~J} * \mathrm{~s}\right), c$ is the light velocity $\left(2.998^{*} 10^{8}\right.$ $\mathrm{m} / \mathrm{s})$.

\subsection{Retrieval of LST with atmospherically corrected thermal data}

Another method adopted in this study for the determination of the LST takes into account the atmospheric correction of the band TM6.

The atmospheric effects include absorption, upward emission, and downward irradiance reflected from the surface and can cause signal distortion [18]. An atmospheric correction is possible if local values for several meteorological parameters are available.

A NASA web tool allows to compute the local values for upwelling $\left(\mathrm{L}_{\mathrm{up}}\right)$ and downwelling $\left(\mathrm{L}_{\mathrm{d}}\right)$ radiances, transmittance $(\tau)$. The web tool requires to enter specific data such as date and time, latitude and longitude [19] [20]. It consents also to insert optional parameters such as local 
altitude, pressure, temperature and relative humidity. Then the atmospheric correction for thermal band is performed using the following equation from Coll [21]:

$$
L_{C}=\frac{L_{s a t}-L_{u p}}{\varepsilon \cdot \tau}-\frac{1-\varepsilon}{\varepsilon} \cdot L_{d}
$$

where, $\mathrm{L}_{\mathrm{C}}$ is the atmospherically corrected radiance, $\mathrm{L}_{\mathrm{sat}}$ is the spectral radiance $\left(\mathrm{W} / \mathrm{m}^{2} * \mathrm{sr}^{*} \mu \mathrm{m}\right), \mathrm{L}_{\mathrm{up}}$ and $\mathrm{L}_{\mathrm{d}}$ are the upwelling and downwelling radiances $\left(\mathrm{W} / \mathrm{m}^{2} * \mathrm{sr}^{*} \mu \mathrm{m}\right), \tau$ and $\varepsilon$ are transmittance and emissivity respectively (adimensional).

The emissivity can be considered as a constant value, 0.95 tipically [22], or variable. In this study, three cases are considered for emissivity values:

1) $\varepsilon=0.95$

2) $\varepsilon=a+b * \ln (N D V I)$;

3) emissivity as from Sobrino [3].

Then, the inverse Planck's law is adopted to compute the temperatures:

$$
L S T=\frac{K_{2}}{\ln \left(\frac{K_{1}}{L_{C}}+1\right)}
$$

\section{Results and discussion}

In this section, five methods are applied to determine the LST from Lansat TM5 data. The results are compared with the values of temperature acquired by the thermal spectrometer of MIVIS sensor.

The temperature data are not affected by the atmospheric effects like as satellite images, because the acquisition is performed at an altitude of $1500 \mathrm{~m}$. The LST retrieval methods are described below:

Method 1: LST is calculated by Eq. (13), taking into account Eq. (7) for the emissivity.

Method 2: this method, like the previous one, considers the Eq. (13) for surface temperature, but uses the emissivity obtained as described from Sobrino [3].

Method 3: the atmospherically corrected radiances Eq. (14) is used to determine LST by Eq. (15). In this method, emissivity has a constant value of 0.95 .

Method 4: this method is similar to the above but uses variable emissivity. The emissivity is computed by NDVI method Eq. (7).

Method 5: in this case, LST is calculated by Eq. (15) and taking into account Sobrino [3] for the emissivity.

The LST obtained with the proposed methods are compared with MIVIS temperatures for several types of land cover. The test areas are selected considering NDVI thresholds. Test pixels are considered for bare soil cover $(0$ $<$ NDVI $<0.1$ ), fully vegetated areas (NDVI $>0.5)$ and a mixture of soil-vegetation cover $(0.1<\mathrm{NDVI}<0.5)$. For identifying test areas, it is also used a false colors image ( $\mathrm{R}$ $=\mathrm{TM} 4 ; \mathrm{G}=\mathrm{TM} 3 ; \mathrm{B}=\mathrm{TM} 2)$. In this image vegetated areas are red.
Fifteen test areas are considered for each type of land cover and these are numbered in the following way: 01, 02, 03, 04, 05, 06, 07, 08, 09, 10, 11, 12 13, 14, 15. The test sites are also labelled with a symbol for each type of land cover considered (S for bare soil, SV for soil-vegetation covers and V for fully vegetated areas; see Fig. 2).

Tab. 1 shows the comparison between the MIVIS temperature and the one obtained by the proposed methods for the bare soil cover. It can be seen that the best results corresponds to output of the Method 1 (RMSE $_{\text {Method1-MIVIS }}=$ $\left.1.58^{\circ} \mathrm{C}\right)$. The RMSE values increase for the other methods, particularly for the Method $5\left(\mathrm{RMSE}_{\text {Method5-MIVIS }}=11.43^{\circ} \mathrm{C}\right)$. The results worsen significantly from Method 3, when considering the atmospherically corrected TM6 band [21].

The highest value of temperature is obtained by Method 5 in test site $08\left(\mathrm{LST}_{\text {Method } 5}=52.79^{\circ} \mathrm{C}\right.$, see Tab. 1). It can also notice that the temperature measured at the satellite $\left(\mathrm{T}_{\mathrm{TOA}}\right)$, without considering the atmospheric and surface emissivity effects, is always less than that gained from the airborne thermal spectrometer and the values obtained by the considered methods. The RMSE value improves on fully vegetated areas (NDVI $>0.5$ ) for Method 3, Method 4 and Method 5, while it worsens for Method 1 (RMSE Method1-MIVIS $_{\text {. }}$ $=2.29^{\circ} \mathrm{C}$, see Tab. 2). Also in this case, $\mathrm{T}_{\mathrm{TOA}}$ is less than the MIVIS temperatures and those computed by the other methods. The LST for Method 3 is $37.68^{\circ} \mathrm{C}$ and it differs most of all on the temperature acquired by MIVIS. For a soil-vegetation mixture cover, the $\mathrm{RMSE}_{\mathrm{s}}$ are lower than those obtained for bar soil cover, but confirm the trends observed for this case, essentially.

Tab. 4 shows the comparison between the different methods. It can be seen that the best $\mathrm{RMSE}_{\mathrm{s}}$ derive from the comparison between related methods (methods with and without atmospheric correction for TM6 band). The worst result is the comparison between the Method 2 and the Methods 4 and 5, for soil-vegetation mixture (RMSE $\mathrm{Methods2-4}$ and $\mathrm{RMSE}_{\text {Methods2-5 }}$ are of $14.66^{\circ} \mathrm{C}$ ).

An increase of RMSE can also be highlighted for methods with a constant value of emissivity. This occurs especially for bare soil and soil-vegetation mixture covers. Method 2 and Method 5 use an emissivity of 0.97 for bare soil cover and 0.99 for fully vegetated areas. Method 3 assumes $\varepsilon=0.95$ for all cover types (Tab. 5, 6, 7).

For fully vegetated areas can be observed similar values of emissivity for all methods, this could justify a reduction in RMSE.

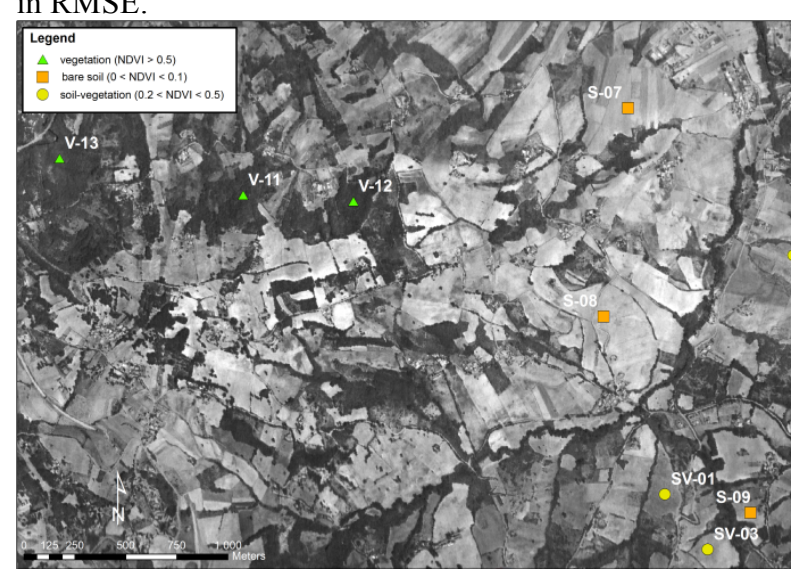

Fig. 2 Test sites on MIVIS Thermal Infrared image (band 100) 
Table 1. Comparison of temperatures of bare soil cover

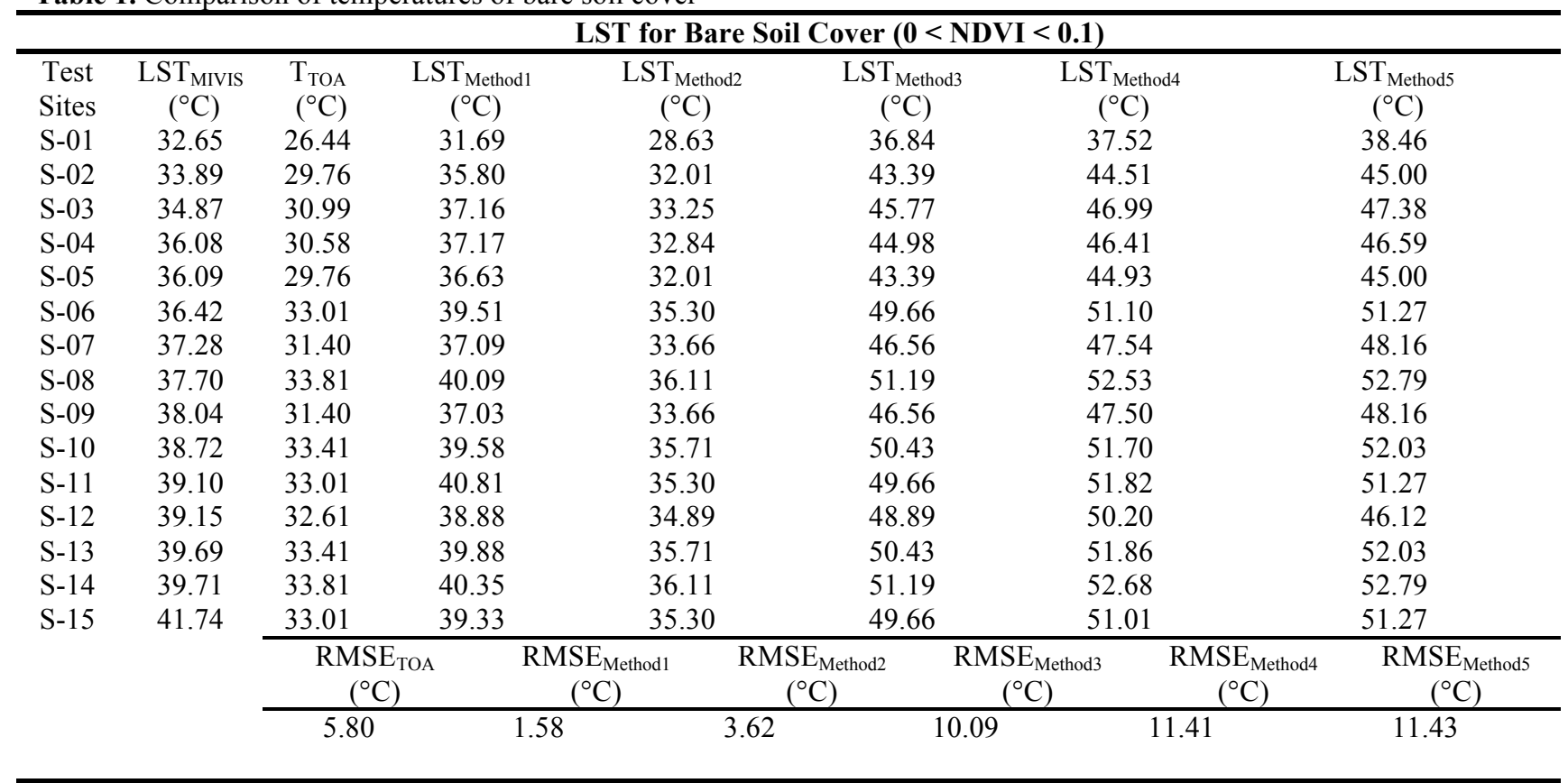

$\mathrm{LST}_{\mathrm{MIVIS}}=\mathrm{LST}$ acquired by thermal camera on board MIVIS; $\mathrm{T}_{\mathrm{TOA}}=$ Brightness Temperature to Top of Atmosphere;

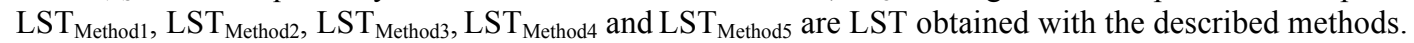

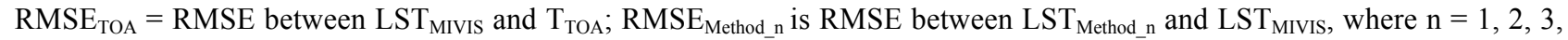
4,5 .

Table 2. Comparison of temperatures of fully vegetated areas

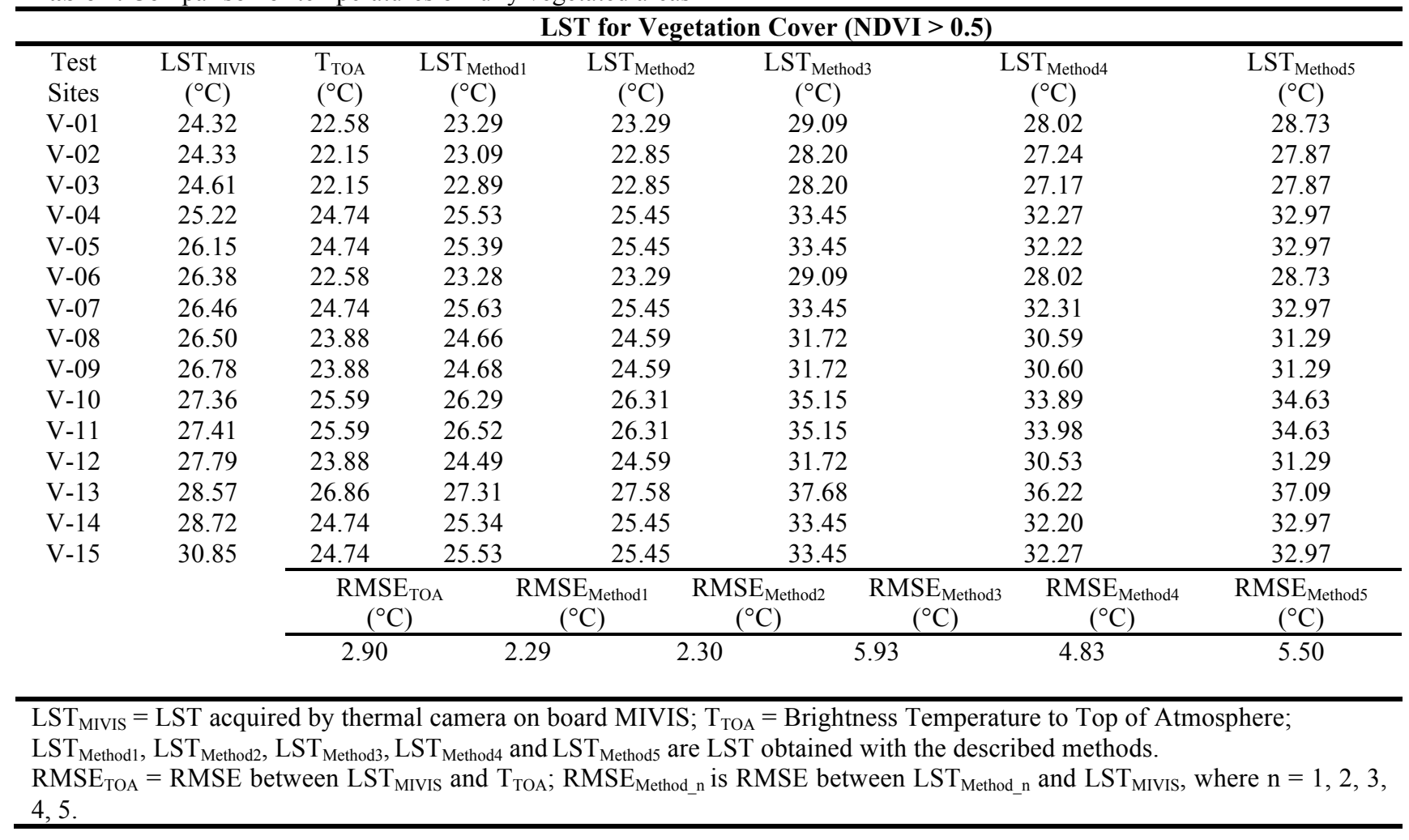


Table 3. Comparison between temperatures for a mixture of soil and vegetation covers

\begin{tabular}{|c|c|c|c|c|c|c|c|}
\hline \multirow[b]{2}{*}{ Test Sites } & \multicolumn{7}{|c|}{ LST for Soil - Vegetation Cover $(0.2<$ NDVI $<0.5)$} \\
\hline & $\begin{array}{c}\mathrm{LST}_{\text {MIVIS }} \\
\left({ }^{\circ} \mathrm{C}\right)\end{array}$ & $\begin{array}{l}\mathrm{T}_{\mathrm{TOA}} \\
\left({ }^{\circ} \mathrm{C}\right)\end{array}$ & $\begin{array}{c}\text { LST }_{\text {Method } 1} \\
\left({ }^{\circ} \mathrm{C}\right)\end{array}$ & $\begin{array}{c}\text { LST }_{\text {Method2 }} \\
\left({ }^{\circ} \mathrm{C}\right)\end{array}$ & $\begin{array}{c}\mathrm{LST}_{\text {Method3 }} \\
\left({ }^{\circ} \mathrm{C}\right)\end{array}$ & $\begin{array}{c}\mathrm{LST}_{\text {Method4 }} \\
\left({ }^{\circ} \mathrm{C}\right)\end{array}$ & $\begin{array}{c}\mathrm{LST}_{\text {Method5 }} \\
\left({ }^{\circ} \mathrm{C}\right)\end{array}$ \\
\hline SV-01 & 30.39 & 27.28 & 30.14 & 28.21 & 38.51 & 38.11 & 38.21 \\
\hline SV-02 & 30.43 & 26.86 & 29.88 & 27.80 & 37.68 & 37.36 & 37.42 \\
\hline SV-03 & 31.05 & 26.44 & 29.08 & 27.34 & 36.84 & 36.37 & 36.55 \\
\hline SV-04 & 31.28 & 29.35 & 33.41 & 30.37 & 42.59 & 42.72 & 42.31 \\
\hline SV-05 & 32.01 & 27.69 & 30.68 & 28.64 & 39.33 & 38.98 & 39.03 \\
\hline SV-06 & 32.44 & 28.11 & 31.46 & 29.09 & 40.15 & 39.96 & 39.88 \\
\hline SV-07 & 32.66 & 30.17 & 34.63 & 31.21 & 44.19 & 44.52 & 43.89 \\
\hline SV-08 & 33.28 & 28.94 & 31.27 & 29.81 & 41.78 & 41.08 & 41.29 \\
\hline SV-09 & 33.88 & 30.17 & 32.54 & 31.05 & 44.19 & 43.46 & 43.65 \\
\hline SV-10 & 34.12 & 31.40 & 35.24 & 32.42 & 46.56 & 46.56 & 46.18 \\
\hline SV-11 & 34.82 & 30.99 & 33.89 & 31.94 & 45.77 & 45.30 & 45.31 \\
\hline SV-12 & 35.48 & 30.99 & 34.69 & 32.00 & 45.77 & 45.71 & 45.40 \\
\hline SV-13 & 35.70 & 33.01 & 37.28 & 34.06 & 49.66 & 49.88 & 49.24 \\
\hline SV-14 & 35.73 & 30.99 & 35.09 & 32.02 & 45.77 & 45.91 & 45.43 \\
\hline \multirow[t]{3}{*}{$\mathrm{SV}-15$} & 36.05 & 33.41 & 37.36 & 34.45 & 50.43 & 50.46 & 49.97 \\
\hline & & $\begin{array}{c}\mathrm{RMSE}_{\mathrm{TOA}} \\
\left({ }^{\circ} \mathrm{C}\right)\end{array}$ & $\begin{array}{c}\text { RMSE }_{\text {Method } 1} \\
\left({ }^{\circ} \mathrm{C}\right)\end{array}$ & $\begin{array}{c}\mathrm{RMSE}_{\text {Method2 }} \\
\left({ }^{\circ} \mathrm{C}\right)\end{array}$ & $\begin{array}{c}\mathrm{RMSE}_{\text {Method3 }} \\
\left({ }^{\circ} \mathrm{C}\right)\end{array}$ & $\begin{array}{c}\mathrm{RMSE}_{\text {Method4 }} \\
\left({ }^{\circ} \mathrm{C}\right)\end{array}$ & $\begin{array}{c}\text { RMSE }_{\text {Method } 5} \\
\left({ }^{\circ} \mathrm{C}\right)\end{array}$ \\
\hline & & 3.68 & 1.38 & 2.75 & 10.03 & 10.15 & 9.92 \\
\hline $\begin{array}{l}\mathrm{LST}_{\text {MIVIS }}=\mathrm{L} \\
\mathrm{LST}_{\text {Method } 1}, \mathrm{~L} \\
\mathrm{RMSE}_{\mathrm{TOA}}= \\
4,5 .\end{array}$ & $\begin{array}{l}\text { quired by } \\
\text { ood2, } \mathrm{LST}_{\mathrm{M}} \\
\mathrm{E} \text { between }\end{array}$ & $\begin{array}{l}\text { rmal camer } \\
{ }_{3}, \mathrm{LST}_{\text {Method }} \\
\mathrm{T}_{\text {MIVIS }} \text { and }\end{array}$ & $\begin{array}{l}\text { n board MIVI } \\
\text { id } \mathrm{LST}_{\text {Method5 }} \\
\text {; RMSE } \\
\text { Meth }\end{array}$ & $\begin{array}{l}\mathrm{T}_{\mathrm{TOA}}=\text { Bright } \\
\mathrm{LST} \text { obtained } \\
\text { is RMSE bet }\end{array}$ & $\begin{array}{l}\text { ss Temperatur } \\
\text { ith the describ } \\
\text { en } \text { LST }_{\text {Method_n }}\end{array}$ & $\begin{array}{l}\text { o Top of Atmo } \\
\text { methods. } \\
\text { i } \text { LST }_{\text {MIVIS }}, \mathrm{W}\end{array}$ & $n=1,2,3$ \\
\hline
\end{tabular}

Table 4. Comparison of RMSE of the LSTs for several land cover types

\begin{tabular}{cccc}
\hline RMSE $\left({ }^{\circ} \mathrm{C}\right)$ & $0<\mathrm{NDVI}<0.1$ & $0.2<\mathrm{NDVI}<0.5$ & NDVI $>0.5$ \\
\hline RMSE $_{\text {Methods1-2 }}$ & 4.07 & 2.49 & 0.13 \\
RMSE $_{\text {Methods1-3 }}$ & 9.32 & 10.31 & 7.53 \\
RMSE $_{\text {Methods1-4 }}$ & 10.64 & 10.13 & 6.37 \\
RMSE $_{\text {Methods1-5 }}$ & 10.65 & 9.94 & 7.08 \\
RMSE $_{\text {Methods2-3 }}$ & 13.33 & 12.73 & 7.55 \\
RMSE $_{\text {Methods2-4 }}$ & 14.66 & 12.58 & 6.39 \\
RMSE $_{\text {Methods2-5 }}$ & 14.66 & 12.37 & 7.10 \\
RMSE $_{\text {Methods3-4 }}$ & 1.35 & 0.37 & 1.17 \\
RMSE $_{\text {Methods3-5 }}$ & 1.71 & 0.37 & 0.45 \\
RMSE $_{\text {Methods4-5 }}$ & 1.14 & 0.35 & 0.72
\end{tabular}

RMSE $_{\text {Methods1-2 }}=$ RMSE between Method 1 and Method 2; RMSE Methods1-3 $_{2}$ RMSE between Method 1 and Method 3; $\mathrm{RMSE}_{\text {Methods1-4 }}=$ RMSE between Method 1 and Method 4; RMSE Methods1-5 $=$ RMSE between Method 1 and Method 5;

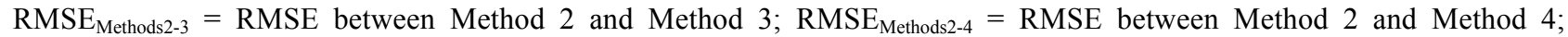

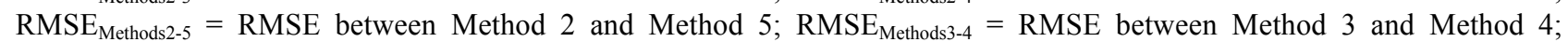
RMSE $_{\text {Methods3-5 }}=$ RMSE between Method 3 and Method 5; RMSE Methods4-5 $=$ RMSE between Method 4 and Method 5.

Table 5. Comparison of emissivity used in the considered methods for bare soil cover

\begin{tabular}{|c|c|c|c|c|c|}
\hline \multicolumn{6}{|c|}{ Emissivity for Bar Soil Cover $(0<$ NDVI $<0.1)$} \\
\hline Test Sites & $\varepsilon_{\text {Method } 1}$ & $\varepsilon_{\text {Method2 }}$ & $\varepsilon_{\text {Method3 }}$ & $\varepsilon_{\text {Method4 }}$ & $\varepsilon_{\text {Method5 }}$ \\
\hline S-01 & 0.919 & 0.97 & 0.95 & 0.919 & 0.97 \\
\hline S-02 & 0.920 & 0.97 & 0.95 & 0.920 & 0.97 \\
\hline S-03 & 0.903 & 0.97 & 0.95 & 0.903 & 0.97 \\
\hline S-04 & 0.918 & 0.97 & 0.95 & 0.918 & 0.97 \\
\hline S-05 & 0.928 & 0.97 & 0.95 & 0.928 & 0.97 \\
\hline S-06 & 0.916 & 0.97 & 0.95 & 0.916 & 0.97 \\
\hline S-07 & 0.921 & 0.97 & 0.95 & 0.921 & 0.97 \\
\hline S-08 & 0.927 & 0.97 & 0.95 & 0.927 & 0.97 \\
\hline S-09 & 0.930 & 0.97 & 0.95 & 0.930 & 0.97 \\
\hline S-10 & 0.912 & 0.97 & 0.95 & 0.912 & 0.97 \\
\hline S-11 & 0.918 & 0.97 & 0.95 & 0.918 & 0.97 \\
\hline $\mathrm{S}-12$ & 0.921 & 0.97 & 0.95 & 0.921 & 0.97 \\
\hline S-13 & 0.922 & 0.97 & 0.95 & 0.922 & 0.97 \\
\hline
\end{tabular}


M. B. Giannini, O. R. Belfiore, C. Parente and R. Santamaria/Journal of Engineering Science and Technology Review 8 (3) (2015) 83 - 90
S-14
0.926
0.97
0.95
0.926
0.97
S-15
0.922
0.97
0.95
0.922
0.97

\begin{tabular}{ccc}
\hline RMSE $_{\text {Method 1-2 }}$ & RMSE $_{\text {Method 2-3 }}$ & RMSE $_{\text {Method 1-3 }}$ \\
\hline 0.05 & 0.02 & 0.031 \\
\hline
\end{tabular}

$\varepsilon_{\text {Methodland } 4}=1.0094+0.047 \cdot \ln (\mathrm{NDVI}) ; \varepsilon_{\text {Method2 and5 }}$ from Sobrino [3]; $\varepsilon_{\text {Method3 }}$ from Coll [21]; RMSE ${ }_{\text {Method 1-2 }}=$ RMSE between $\varepsilon_{\text {Method1 }}$ and $\varepsilon_{\text {Method2 }}$; RMSE $E_{\text {Method 2-3 }}=$ RMSE between $\varepsilon_{\text {Method2 }}$ and $\varepsilon_{\text {Method } 3}$; RMSE $E_{\text {Method 1-3 }}=$ RMSE between $\varepsilon_{\text {Method1 }}$ and $\varepsilon_{\text {Method3. }}$

Table 6. Comparison of temperatures fully vegetated areas

\begin{tabular}{|c|c|c|c|c|c|}
\hline \multicolumn{6}{|c|}{ Emissivity for Vegetation Cover (NDVI > 0.5) } \\
\hline Test Sites & $\varepsilon_{\text {Method1 }}$ & $\varepsilon_{\text {Method2 }}$ & $\varepsilon_{\text {Method3 }}$ & $\varepsilon_{\text {Method4 }}$ & $\varepsilon_{\text {Method5 }}$ \\
\hline V-01 & 0.988 & 0.99 & 0.95 & 0.988 & 0.99 \\
\hline $\mathrm{V}-02$ & 0.994 & 0.99 & 0.95 & 0.994 & 0.99 \\
\hline $\mathrm{V}-03$ & 0.992 & 0.99 & 0.95 & 0.992 & 0.99 \\
\hline $\mathrm{V}-04$ & 0.991 & 0.99 & 0.95 & 0.991 & 0.99 \\
\hline $\mathrm{V}-05$ & 0.984 & 0.99 & 0.95 & 0.984 & 0.99 \\
\hline $\mathrm{V}-06$ & 0.976 & 0.99 & 0.95 & 0.976 & 0.99 \\
\hline $\mathrm{V}-07$ & 0.989 & 0.99 & 0.95 & 0.989 & 0.99 \\
\hline $\mathrm{V}-08$ & 0.991 & 0.99 & 0.95 & 0.991 & 0.99 \\
\hline V-09 & 0.990 & 0.99 & 0.95 & 0.990 & 0.99 \\
\hline $\mathrm{V}-10$ & 0.987 & 0.99 & 0.95 & 0.987 & 0.99 \\
\hline $\mathrm{V}-11$ & 0.987 & 0.99 & 0.95 & 0.987 & 0.99 \\
\hline $\mathrm{V}-12$ & 0.990 & 0.99 & 0.95 & 0.990 & 0.99 \\
\hline $\mathrm{V}-13$ & 0.990 & 0.99 & 0.95 & 0.990 & 0.99 \\
\hline V-14 & 0.989 & 0.99 & 0.95 & 0.989 & 0.99 \\
\hline \multirow[t]{3}{*}{$\mathrm{V}-15$} & 0.989 & 0.99 & 0.95 & 0.989 & 0.99 \\
\hline & RMSE $_{\text {Method 1-2 }}$ & RMSE $_{\text {Method 2-3 }}$ & RMSE $_{\text {Method 1-3 }}$ & & \\
\hline & 0.004 & 0.040 & 0.039 & & \\
\hline
\end{tabular}

$\varepsilon_{\text {Methodland } 4}=1.0094+0.047 \cdot \ln (\mathrm{NDVI}) ; \varepsilon_{\text {Method2 and5 }}$ from Sobrino [3]; $\varepsilon_{\text {Method3 }}$ from Coll [21]; RMSE $E_{\text {Method 1-2 }}=$ RMSE between $\varepsilon_{\text {Method1 }}$ and $\varepsilon_{\text {Method2 }}$; RMSE $E_{\text {Method 2-3 }}=$ RMSE between $\varepsilon_{\text {Method2 }}$ and $\varepsilon_{\text {Method } 3}$; RMSE $E_{\text {Method 1-3 }}=$ RMSE between $\varepsilon_{\text {Method1 }}$ and $\varepsilon_{\text {Method3 }}$.

Table 7. Comparison of emissivity used in the considered methods for a mixture of soil and vegetation covers

\begin{tabular}{|c|c|c|c|c|c|}
\hline \multicolumn{6}{|c|}{ Emissivity for Soil-Vegetation Cover $(0.2<$ NDVI $<0.5)$} \\
\hline Test Sites & $\varepsilon_{\text {Method1 }}$ & $\varepsilon_{\text {Method2 }}$ & $\varepsilon_{\text {Method3 }}$ & $\varepsilon_{\text {Method4 }}$ & $\varepsilon_{\text {Method5 }}$ \\
\hline SV-01 & 0.959 & 0.987 & 0.95 & 0.959 & 0.987 \\
\hline SV-02 & 0.946 & 0.986 & 0.95 & 0.946 & 0.986 \\
\hline SV-03 & 0.942 & 0.986 & 0.95 & 0.942 & 0.986 \\
\hline SV-04 & 0.955 & 0.987 & 0.95 & 0.955 & 0.987 \\
\hline SV-05 & 0.945 & 0.986 & 0.95 & 0.945 & 0.986 \\
\hline SV-06 & 0.960 & 0.987 & 0.95 & 0.960 & 0.987 \\
\hline SV-07 & 0.975 & 0.989 & 0.95 & 0.975 & 0.989 \\
\hline SV-08 & 0.961 & 0.987 & 0.95 & 0.961 & 0.987 \\
\hline SV-09 & 0.950 & 0.986 & 0.95 & 0.950 & 0.986 \\
\hline SV-10 & 0.952 & 0.986 & 0.95 & 0.952 & 0.986 \\
\hline SV-11 & 0.947 & 0.986 & 0.95 & 0.947 & 0.986 \\
\hline SV-12 & 0.962 & 0.987 & 0.95 & 0.962 & 0.987 \\
\hline SV-13 & 0.945 & 0.986 & 0.95 & 0.945 & 0.986 \\
\hline SV-14 & 0.969 & 0.988 & 0.95 & 0.969 & 0.988 \\
\hline \multirow[t]{3}{*}{ SV-15 } & 0.949 & 0.986 & 0.95 & 0.949 & 0.986 \\
\hline & RMSE $_{\text {Method 1-2 }}$ & RMSE $_{\text {Method 2-3 }}$ & RMSE $_{\text {Method 1-3 }}$ & & \\
\hline & 0.033 & 0.037 & 0.010 & & \\
\hline
\end{tabular}




\section{Conclusions}

In this study, five approaches for the LST retrieval, from Landsat TM5 data, are presented. The first two, Method 1 and Method 2, compute the land surface temperatures by Eq. (13) and considering NDVI methods for the emissivity estimation. The other methods obtain LST considering atmospheric correction for the thermal infrared band and an emissivity which is considered: constant for the first of them (Method 3), and variable, obtained with NDVI methods, for the others (Method 4 and 5). The results are compared with the land surface temperatures acquired by the MIVIS sensor.

The LST retrieved using Method 1 showes the best RMSE for soil-vegetation mixture cover. The results generally worse for the other methods, in particular when considering constant values for the emissivity. Similar values of LST are observed at vegetated areas and differ greatly for bare soil cover.

Moreover, the obtained results show that the Method 1 is particularly efficient for the estimation of LST in rural areas.

Furthermore, this method could be used to retrieve LST by remote sensed data, acquired from sensors other than Landsat TM5.

\section{Acknowledgements}

This paper synthesizes results of works performed within the project PRIN 2010-11 financed by MIUR (Ministero dell'Istruzione, dell'Università e della Ricerca) - Italy and developed at the University of Naples "Parthenope" (Coordinator: Prof. Raffaele Santamaria).

\section{References}

1. J.C. Price, Estimating surface temperature from satellite thermal infrared data - A simple formulation for the atmospheric effect, Remote Sensing of Environment, vol.13(4), pp. 353-361 (1983).

2. J.A. Sobrino, Z. L. Li, M. P. Stoll, and F. Becker, Multi-channel and multi-angle algorithms for estimating sea and land surface temperature with ATSR data, International Journal of Remote Sensing, vol.17(11), pp. 2089-2114 (1996).

3. J. A. Sobrino, J. C. Jiménez-Muñoz and L. Paolini, Land surface temperature retrieval from LANDSAT TM 5, Remote Sensing of Environment, vol.90(4), pp. 434-440(2004).

4. J. C. Price, Land surface temperature measurements from the split window channels of the NOAA-7 AVHRR, Journal of Geophysical Research: Atmospheres (1984-2012), vol.89(D5), pp. 7231-7237 (1984).

5. A. A. Van de Griend and M. Owe, On the relationship between thermal emissivity and the Normalized Difference Vegetation Index for natural surfaces, International Journal of Remote Sensing, vol.14(6), pp. 1119-1131 (1993).

6. E. Valor and V. Caselles, Mapping land surface emissivity from NDVI: application to European, African and South American areas, Remote Sensing of Environment, vol.57(3), pp. 167-184. (1996).

7. F. Li, T. J. Jackson, W. P. Kustas, T. J. Schmugge, A. N. French, M. H. Cosh and R. Bindlish, Deriving land surface temperature from Landsat 5 and 7 during SMEX02/SMACEX, Remote Sensing of Environment, vol.92(4), pp. 521-534 (2004).

8. Z. Wan and J. Dozier, A generalized split-window algorithm for retrieving land-surface temperature from space, Geoscience and Remote Sensing, IEEE Transactions on, vol.34(4), pp. 892905(1996).

9. G. Chander and B. Markham, Revised Landsat-5 TM Radiometric Calibration Procedures and Postcalibration Dynamic Ranges, IEEE Transactions on Geoscience and Remote Sensing, vol.41(11), pp. 2674-2677 (2003).

20. Proceedings,2003 IEEE International, vol.5, pp. 3014-3016 (2003)

21. J.A. Barsi, J.R. Schott, F.D. Palluconi and S.J. Hook, Validation of a web-based atmospheric correction tool for single thermal band instruments, In: Optics \& Photonics 2005, International Society for Optics and Photonics, pp. 58820E58820E-7(2005).

22. C. Coll, J. M. Galve, J. M. Sánchez, and V. Caselles, Validation of Landsat-7/ETM+ thermal-band calibration and atmospheric correction with ground-based measurements, Geoscience and Remote Sensing, IEEE Transactions on, vol. 48(1), pp. 547-555 (2010).

23. P.S.Kealy and S.J.Hook, Separating temperature and emissivity in thermal infrared multispectral scanner data: implications for recovering land surface temperatures. Geoscience and Remote Sensing IEEE Transactions on, vol.31(6), pp. 1155-1164 (1993).
10. M. Basile Giannini, T. Creta, D. Guglietta, P. Merola and A. Allegrini, Methodologies to identify asbestos-cement roofing by remote data, Italian Journal of Remote Sensing, vol.44(1): pp. 2737 (2012).

11. P. S. Chavez, Image-Based Atmospheric Corrections - Revisited and Improved, Photogrammetric Engineering \& Remote Sensing, vol.62(9), pp. 1025-1036 (1996).

12. M. S. Moran, R. D. Jackson, P. N. Slater and P. M. Teillet, Evaluation of simplified procedures for retrieval of land surface reflectance factors from satellite sensor output, Remote Sensing of Environment, vol.41(2), pp.169-184 (1992).

13. W. C. Snyder, Z. Wan, Y. Zhang and Y. Z. Feng, Classification based emissivity for land surface temperature measurement from space, International Journal of Remote Sensing, vol.19(14), pp. 2753-2774 (1998).

14. P.A. Brivio, G. Lechi, and E. Zilioli, Principi e metodi di telerilevamento, CittàStudi Edizioni, Torino, pp. 449,479 (2006).

15. J. A. Sobrino, V. Caselles and F. Becker, Significance of the remotely sensed thermal infrared measurements obtained over a citrus orchard, ISPRS Photogrammetric Engineering and Remote Sensing, vol.44(6), pp. 343-354 (1990).

16. T. N. Carlson and D. A. Ripley, On the relation between NDVI, fractional vegetation cover, and leaf area index, Remote Sensing of Environment, vol.62(3), pp. 241-252 (1997).

17. D.A. Artis and W.H. Carnahan, Survey of emissivity variability in thermography of urban areas, Remote Sensing of Environment, vol.12(4), pp. 313-329 (1982).

18. G. B. Franc and A. P. Cracknell, Retrieval of land and sea surface temperature using NOAA-11 AVHRR data in north-eastern Brazil, International Journal of Remote Sensing, vol.15(8), pp.1695-1712; (1994).

19. J.A. Barsi, J.L. Barker and J.R. Schott, An atmospheric correction parameter calculator for a single thermal band earthsensing instrument, In: Geoscience and Remote Sensing Symposium, 2003.2 IGARSS'03. 